TITLE:

\title{
The effects of displacement threshold irradiation energy on deep levels in p-type $6 \mathrm{H}$-SiC
}

$\operatorname{AUTHOR}(\mathrm{S})$ :

Alfieri, Giovanni; Kimoto, T

\section{CITATION:}

Alfieri, Giovanni ... [et al]. The effects of displacement threshold irradiation energy on deep levels in p-type 6H-SiC. Journal of Physics: Condensed Matter 2011, 23(6): 065803.

\section{ISSUE DATE:}

2011-02-16

URL:

http://hdl.handle.net/2433/138534

\section{RIGHT:}

(C) IOP Publishing 2011; この論文は出版社版でありません。引用の際に は出版社版をご確認ご利用ください。; This is not the published version. Please cite only the published version. 


\title{
The effects of displacement threshold irradiation energy on deep levels in p-type $6 \mathrm{H}-\mathrm{SiC}$
}

\author{
G Alfieri ${ }^{1}$, T Kimoto ${ }^{1,2}$ \\ ${ }^{1}$ Department of Electronic Science and Engineering, Kyoto University, \\ Kyotodaigaku-katsura, Nishikyo, Kyoto 615-8510, Japan \\ ${ }^{2}$ Photonics and Electronics Science and Engineering Center, Kyoto University, \\ Kyotodaigaku-katsura, Nishikyo, Kyoto 615-8510, Japan \\ E-mail: giovanni@semicon.kuee.kyoto-u.ac.jp
}

\begin{abstract}
We report on the electrical characterization, by means of deep level transient spectroscopy (DLTS), of electron irradiated Al-doped 6H-SiC epilayers. Samples were irradiated with either $116 \mathrm{keV}$, in order to displace only carbon atoms, or $400 \mathrm{keV}$ and seven deep traps, in the $0.1-1.6 \mathrm{eV}$ range above the valence band, were found. The thermal stability of the detected levels was analyzed by performing an isochronal annealing series in the $100-1800{ }^{\circ} \mathrm{C}$ temperature range and the atomic structure of most of the detected traps was found to be related to C-displacement.
\end{abstract}

PACS numbers: $61.82 . \mathrm{Fk}, 61.72 . \mathrm{Cc}$ 


\section{Introduction}

Despite its attractive physical and chemical properties [1], several factors still hinder the use of silicon carbide $(\mathrm{SiC})$ as a replacement of $\mathrm{Si}$ for a wide range of electronic applications. For instance, cost has prevented $\mathrm{SiC}$ from being economically viable but, as it was recently reported [2], 6-inch $\mathrm{SiC}$ substrates with micropipe densities lower than $10 \mathrm{~mm}^{-2}$ are expected to reduce manufacturing costs thus making SiC-based devices, such as diodes or bipolar transistors, more widely available.

Another issue is the presence of electrically active point defects. These defects, which are present in the as-grown material and can also be generated after particle irradiation, are a well-known cause for the malfunction of $\mathrm{SiC}$ electronic devices because they can act as recombination centers and decrease carriers lifetime. The $Z_{1 / 2}$ in $n$-type material is a notorious example of lifetime-killing defect and its electrical properties and atomic structure have been studied intensively in the past $[3,4,5,6,7]$.

On the contrary, due to the difficulty of finding suitable ohmic contacts and because of lower doping activation percentage, not much effort was devoted to the study of electrically active point defects in $p$-type material. In the last few years, deep level transient spectroscopy (DLTS) studies performed on Al-doped 4H-SiC have appeared in the literature $[8,9,10]$ and, recently, on $6 \mathrm{H}-\mathrm{SiC}$ polytype, as well $[11,12,13]$.

DLTS on as-grown [11] and high-energy electron irradiated [12] Al-doped 6H-SiC, have revealed the presence of several traps, but apart from the identification of the D-center and the B-acceptor, the microscopic nature of the other defects is still an unanswered question. In order to investgate the atomic structure of these defects, we carried out an electrical characterization study of p-type $6 \mathrm{H}-\mathrm{SiC}$ epilayers irradiated with $116 \mathrm{keV}$ (to displace only $\mathrm{C}$ atoms) or $400 \mathrm{keV}$ electrons (to displace both $\mathrm{C}$ and $\mathrm{Si}$ atoms), because this method has proven helpful to unveil the nature of the detected defects $[14,15]$.

\section{Experimental details}

We employed $10 \mu \mathrm{m}$ thick Al-doped $6 \mathrm{H}-\mathrm{SiC}$ epilayers $\left(N_{a} \sim 10^{16} \mathrm{~cm}^{-3}\right)$ irradiated with an electron-beam of 116 or $400 \mathrm{keV}$ at room temperature (dose $1 \times 10^{15} \mathrm{~cm}^{-2}$, irradiation time $8 \mathrm{~min}$ ) by NHV Corp. (Kyoto, Japan). Prior to irradiation, a tri-layer of $\mathrm{Ti} / \mathrm{Al} / \mathrm{Ni}$ was deposited by thermal evaporation on the backside of the samples and then sintered for 10 min at $1000^{\circ} \mathrm{C}$.

After irradiation, the samples underwent an isochronal annealing series(time step 15 min) from 100 to $1800^{\circ} \mathrm{C}$ using either a rapid thermal annealing (RTA) furnace or a chemical vapor deposition (CVD) chamber, both in Ar flow, for heat treatments in the $100-1000$ and $1100-1800^{\circ} \mathrm{C}$ range, respectively. For annealing at temperatures above $1100^{\circ} \mathrm{C}$, a carbon cap was employed so to prevent surface decomposition. Each annealing step was followed by the deposition of Ti (diameter $1 \mathrm{~mm}$ ) on the samples surface so to make electrical characterization by Fourier-Transform DLTS possible [16] (reverse bias $6 \mathrm{~V}$, pulse voltage $0 \mathrm{~V}$ and filling pulse width $1 \mathrm{~ms}$ ). Electrical characterization 


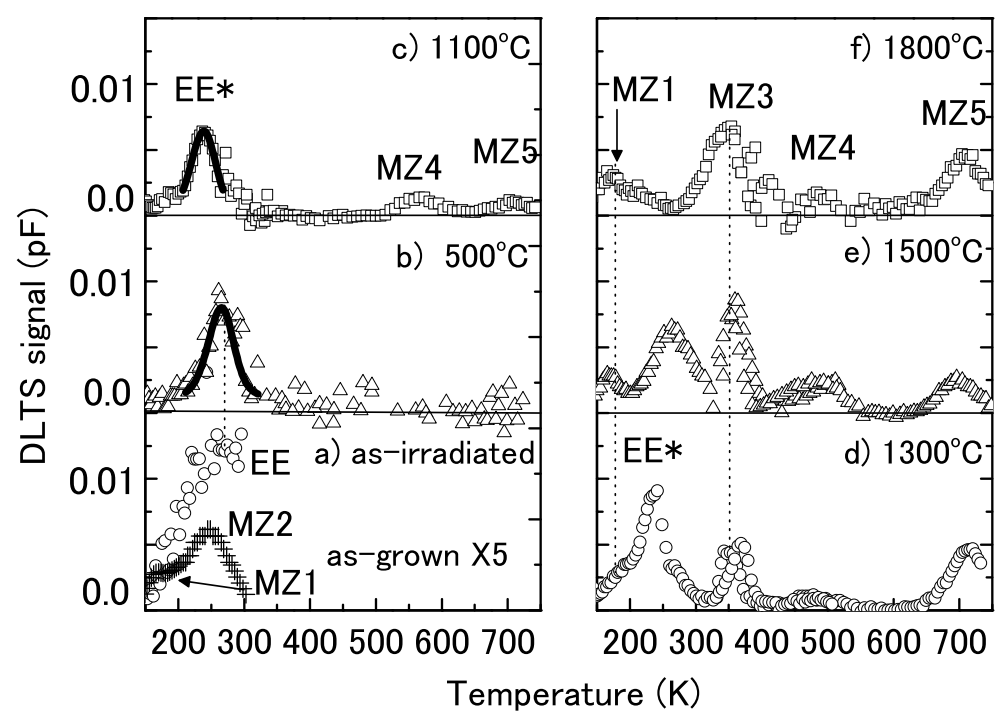

Figure 1. DLTS spectra of the (a) as-irradiated, (b) 500, (c) 1100, (d) 1300, (e) 1500 and (f) $1800{ }^{\circ} \mathrm{C}$ annealed $116 \mathrm{keV}$ electron irradiated samples (period width 0.2 s). In (a) the DLTS spectrum of the as-grown sample $($ magnified $\times 5)$ is added for comparison.

was performed in the $150-700 \mathrm{~K}$ range and for annealing temperatures up to $400^{\circ} \mathrm{C}$ the highest temperature limit of the DLTS measurement was set so to coincide with the annealing temperature.

\section{Results and discussion}

Figure 1 shows the results of the DLTS measurements on the a) as-irradiated (and as-grown sample, for comparison), b) 500, c) 1100 , d) 1300 , e) 1500 and f) $1800{ }^{\circ} \mathrm{C}$ annealed samples after $116 \mathrm{keV} e^{-}$-irradiation, respectively.

In the as-grown sample, two levels are present, MZ1 and MZ2 [11] and after irradiation with $116 \mathrm{keV}$, only one level labelled EE could be detected at around $\sim 280 \mathrm{~K}$. This level is thermally stable after heat treatment at $500^{\circ} \mathrm{C}$ but is annihilated when the sample undergoes heat treatment at $1100^{\circ} \mathrm{C}$. In fact, a new level arises at lower temperatures $(\sim 250 K)$, labelled $\mathrm{EE}^{*}$ and the presence of a small shoulder-shaped peak at lower temperatures $(\sim 180 \mathrm{~K})$ is revealed. In addition, two more DLTS peaks were found at around $\sim 500$ and $\sim 700 \mathrm{~K}$, which we identify as the MZ4 and MZ5, respectively [11]. Subsequent heat treatments (figure 1d) result in the formation of the MZ3 level, previously identified as the D-center [11]. The earlier mentioned shoulder peak, labelled as MZ1 [11] and identified as the B-acceptor, is now more clearly visible next to the $\mathrm{EE}^{*}$ level. Annealing at $1600^{\circ} \mathrm{C}$ results in the annihilation of the $\mathrm{EE}^{*}$ level 


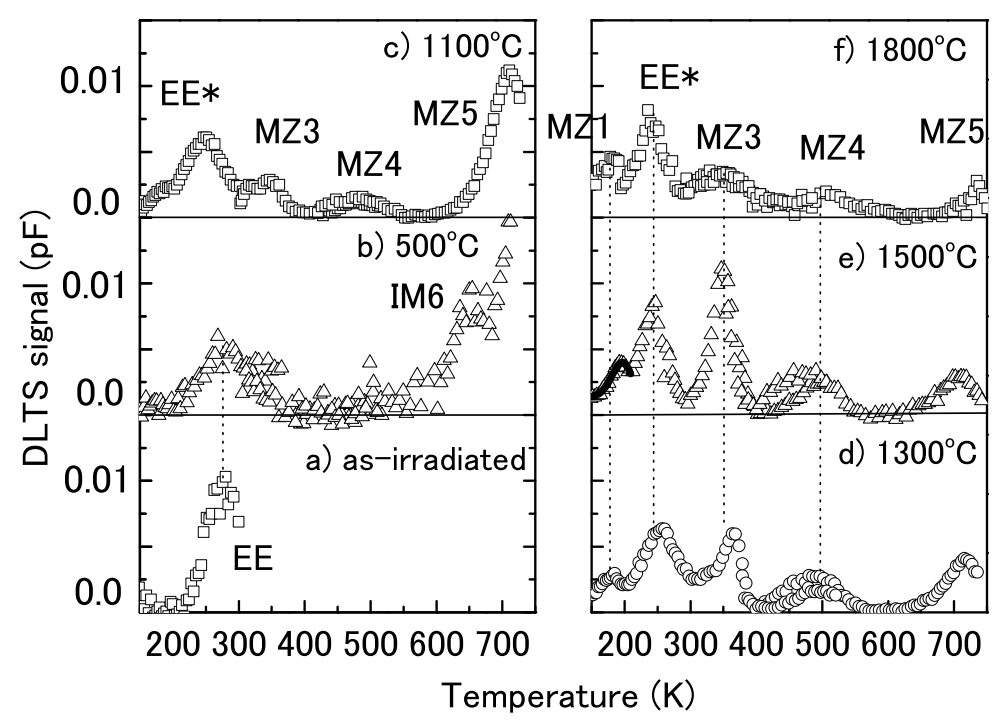

Figure 2. DLTS spectra of the (a) as-irradiated, (b) 500, (c) 1100, (d) 1300, (e) 1500 and (f) $1800{ }^{\circ} \mathrm{C}$ annealed $400 \mathrm{keV}$ electron irradiated samples (period width $0.2 \mathrm{~s}$ ).

while MZ1, MZ3, MZ4 and MZ5 are still present even after $1800^{\circ} \mathrm{C}$.

The DLTS spectra of the $400 \mathrm{keV} e^{-}$-irradiated samples, are presented in figure 2 . In figure 2a, the EE level could be detected in the as-irradiated sample and heat treatments at $500^{\circ} \mathrm{C}$ (Fig. $2 \mathrm{~b}$ ) result in the formation of a defect, in the shape of a shoulder of a bigger DLTS peak that was not detectable due to the temperature limit set in our DLTS measurement. This shoulder has the same thermal stability and energy position of a level detected in $1 \mathrm{MeV} e^{-}$-irradiated $6 \mathrm{H}-\mathrm{SiC}$ and thus identified as the IM6 center [12]. Similarly to the $116 \mathrm{keV}$ irradiated sample, also for the $400 \mathrm{keV}$ irradiates sample, annealing at $1100{ }^{\circ} \mathrm{C}$ gives rise to the $\mathrm{EE}^{*}, \mathrm{MZ} 4$ and MZ5 levels but, in the present case, the MZ1 and MZ3 are more clearly distinguishable. Defects detected after subsequent heat treatments at higher temperatures (figure $2 \mathrm{~d}$ ) show high thermal stability up to $1800{ }^{\circ} \mathrm{C}$.

The energy position in the band gap above the valence band $\left(E_{V}\right)$ and capture-cross sections of the detected levels are reported in Table 1 and due to a rather poor DLTS signal-to-noise ratio we employed a fitting procedure for the FT-DLTS peaks [16] in order to obtain more reliable values of the energy position in the bandgap and capture cross section for the EE, EE* and MZ1 levels (solid lines in figures 1b, 1c and figure 2e). In figure 3, the isochronal annealing behavior of the $\mathrm{EE}$ and $\mathrm{EE}^{*}$ traps is shown. It can be seen that both EE and $\mathrm{EE}^{*}$ display similar concentration values after irradiation with either 116 or $400 \mathrm{keV}$ electrons, with the exception of EE* which, in the case of the $116 \mathrm{keV}$ irradiation, anneals out at $1600^{\circ} \mathrm{C}$. This annealing behavior was modelled according to a first-order annealing process (see Ref. [10] for details) with an activation 
Table 1. Labeling, energy position above $E_{V}$ and capture cross section $(\sigma)$ for the seven detected levels.

\begin{tabular}{llll}
\hline Label & Energy $(\mathrm{eV})$ & $\sigma\left(\mathrm{cm}^{2}\right)$ & Comments \\
\hline EE & $0.31 \pm 0.03$ & $\sim 2 \times 10^{-17}$ & Anneals out below $1100{ }^{\circ} \mathrm{C}$ \\
EE* & $0.28 \pm 0.08$ & $\sim 2 \times 10^{-16}$ & Stable up to $1800{ }^{\circ} \mathrm{C}$ after $400 \mathrm{keV}$ irradiation \\
MZ1 & $0.21 \pm 0.09$ & $\sim 3 \times 10^{-16}$ & Stable up to $1800{ }^{\circ} \mathrm{C}$ \\
MZ3 & $0.57 \pm 0.09$ & $\sim 10^{-16}$ & Stable up to $1800{ }^{\circ} \mathrm{C}$ \\
MZ4 & $0.66 \pm 0.05$ & $\sim 10^{-10}$ & Stable up to $700{ }^{\circ} \mathrm{C}$ \\
MZ5 & $1.60 \pm 0.12$ & $\sim 10^{-12}$ & Stable up to $1800{ }^{\circ} \mathrm{C}$ \\
IM6 & $1.20 \pm 0.45$ & $\sim 3 \times 10^{-13}$ & Anneals out below $1000{ }^{\circ} \mathrm{C}$ \\
\hline
\end{tabular}

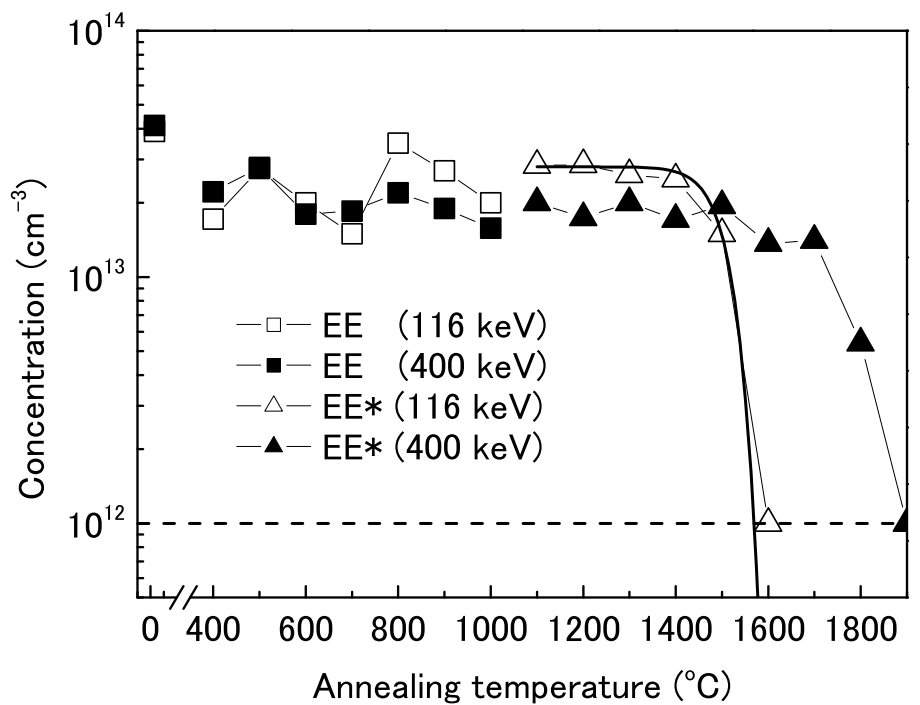

Figure 3. Isochronal annealing behavior of the EE and EE* traps for the 116 and $400 \mathrm{keV}$ electron irradiated samples. The time step was of $15 \mathrm{~min}$. The solid line represents a first order annealing process with an activation energy of $4.8 \mathrm{eV}$ and a pre-exponential factor of $10^{13} \mathrm{~s}^{-1}$. Dashed line represents the detection limit.

energy of $4.8 \mathrm{eV}$.

We now proceed to discuss the nature of the detected defects so to possibly find the presence of C-related defects in $p$-type $6 \mathrm{H}-\mathrm{SiC}$. To do this, we compare the results of the present study with those of previous experimental and theoretical studies found in the literature, as DLTS does not provide any direct information on the microscopic structure of the detected levels.

It can be noted that all the reported levels, with the exception of $\mathrm{EE}$ and $\mathrm{EE}^{*}$, have already been detected in either as-grown or $1 \mathrm{MeV} e^{-}$-irradiated material and their nature discussed in detail. However, we can benefit from the results of the present study to either support or amend the previous conclusions and we start our discussion from 
$\mathrm{EE}$ and $\mathrm{EE}^{*}$, because the existence of shallow levels in p-type $\mathrm{SiC}$ is still an unsolved riddle for theoreticians. Experimental results claimed the such shallow levels could be associated to complexes involving vacancies and doping atoms [17]. However, according to theory, complexes such as $A l_{S i} V_{C}$ or either $B_{S i} C_{i}$ are located well above $E_{V}+0.5 \mathrm{eV}$, thus excluding the possible participation of dopants in the microscopic structure of such levels [17]. This also applies to the levels reported in the present study, EE $\left(E_{V}+0.31\right.$ $\mathrm{eV})$ and $\mathrm{EE}^{*}\left(E_{V}+0.28 \mathrm{eV}\right)$.

$\mathrm{EE}\left(E_{V}+0.31 \mathrm{eV}\right)$ has a very similar energy position of two levels reported in $4 \mathrm{H}-\mathrm{SiC}$ $\left(E_{V}+0.37\right)$ by Matsuura et al. [18] who did not comment on its microscopic structure. A carbon cluster, $\left(C_{i}\right)_{2}$ can be a possible candidate for the EE center: In fact, Bockstedte et al. [19] predicted $\left(C_{i}\right)_{2}$ to be located at cubic sites $(6 \mathrm{H}-\mathrm{SiC}$ has a cubic to hexagonal site ratio of 2:1) and located at $E_{V}+0.38 \mathrm{eV}$ which is very similar to that of $\mathrm{EE}$ and Gali et al. predicted that such cluster should anneal at around $900{ }^{\circ} \mathrm{C}$ [20], which is still the case.

EE* $^{*}\left(E_{V}+0.28 \mathrm{eV}\right)$ arises after annealing at temperatures above $900^{\circ} \mathrm{C}$ and as it can be seen from figure 2, $\mathrm{EE}^{*}$ anneals out after heat treatments at $1600^{\circ} C$ in the $116 \mathrm{keV}$ while it is still present after annealing at $1800{ }^{\circ} \mathrm{C}$, in the $400 \mathrm{keV}$ irradiated sample. This different annealing behavior can be explained if the $\mathrm{EE}^{*}$ level is associated with the $V_{C} S i_{C}$ center because this complex is predicted to anneal out at $1600^{\circ} \mathrm{C}$ with an activation energy of $4.4 \mathrm{eV}$ [21], which is close to that estimated in figure 3 . On the contrary, for the $400 \mathrm{keV}$ irradiated sample, while the $V_{C} S i_{C}$ complex may also break up, the surplus of Si interstitials created by irradiation is such that Si atoms migrate and occupy empty C-sites (which have a very high thermal stabiliy) and consequently build up new $V_{C} S i_{C}$ centers.

Regarding the nature of those levels common to either as-grown or $1 \mathrm{MeV} e^{-}$-irradiated material, the MZ4 level may be too shallow to be related to $\mathrm{Al}$ and since it is present after $116 \mathrm{keV} e^{-}$-irradiation, has high thermal stability and a very close energy position to the Hp1 level found by Storasta et al. [22], after $200 \mathrm{keV} e^{-}$-irradiation in 4H-SiC, we believe that $\mathrm{C}$ may be involved in its microscopic structure. The involvement of $\mathrm{Al}$ in the microscopic structure of the detected defects, may be invoked for the case of the deepest level, the MZ5 level $\left(E_{V}+1.6 \mathrm{eV}\right)$ for which $A l_{S i} V_{C}$ can be a suitable candidate, as theory predicts that this level has very high thermal stability (at least $1700^{\circ} \mathrm{C}$ ) and a level in the gap at $E_{V}+1.5 \mathrm{eV}$ [17]. The nature of the IM6 level was tentatively associated to the $V_{C} C_{S i}$ center [12], yet, as Umeda et al. [23] have reported, when the annealing of such center occurs also the $V_{C}$ should anneal out, while in the present case, only the IM6 anneals out and no other DLTS peak.

It should not be surprising that most of the levels in the present study may be C-related: In fact, in $p$-type material the presence of C-related point defects (e.g, vacancies) is more energetically favorable than that of Si [24]. Moreover, the annealing mechanisms of point defects in $p$-type are different from those that occur in $n$-type. In fact, in p-type $\mathrm{SiC}, \mathrm{C}$ Frenkel-pairs are positively charged and cannot recombine so, by migrating, they can be trapped by doping or build up clusters [19]. The same applies to Si Frenkel pairs 
for which, the migration/recombination energy is higher than that for transformation and, as a result, $V_{S i}$ transforms into a $V_{C} C_{S i}$ complex [19]. This leads us to the question of reproducibility: How different should experimental conditions be, so that similar studies yield different results?

In the study by Luo et al. [13], like in the present one, Cree epilayers with the same doping concentration were irradiated with $400 \mathrm{keV}$ electron energy. However, differently from what expected, striking differences in the DLTS results could be noted, as Luo et al. [13], with the exception of the MZ4 level, reported fewer levels and with lower thermal stability than those found in the present study. Indeed, the different irradiation doses and sample preparation (different annealing time steps) may play a role because these can influence the average distribution and concentration of defects, affecting the vacancy-interstitial recombination/diffusion.

For example, under particular conditions (irradiation dose and/or annealing time) $V_{S i}$ may arise which, due to its instability, transforms into a low thermally stable $V_{C} C_{S i}$ complex. When this complex anneals out, so does also $V_{C}$ [23] thus explaining why no defect survives $1600^{\circ} \mathrm{C}$ annealing. Furthermore, the use of Au Schottky diodes by Luo et al. [13], in contrast to Ti used in the present study, may also contribute to explain the differences, as in $p$-type $6 \mathrm{H}-\mathrm{SiC} \mathrm{Au}$ has a smaller Schottky barrier than $\mathrm{Ti}$ [25] which should yield a higher leakage current and worsening of the signal-to-noise ratio, making the detection of minor DLTS peak difficult.

\section{Conclusions}

In conclusion, we identified seven levels in the $0.21-1.6 \mathrm{eV}$ range above $E_{V}$, in $p$-type $6 \mathrm{H}-\mathrm{SiC}$ epilayers, after irradiation with 116 or $400 \mathrm{keV}$. The microscopic structure of all of the detected levels, with the exception of MZ1 and IM6, was related to carbon displacement and the discrepancies with a similar study were explained by invoking the presence of the $V_{S i}$ whose annealing mechanism in $p$-type material follows a different path than that of $n$-type.

\section{Acknowledgements}

This work was supported by the Japanese Society for the Promotion of Science and by the Global COE Program (C09) from the Ministry of Education, Culture, Sports and Technology, Japan.

\section{References}

[1] Matsunami H, Kimoto T 1997 Mater. Sci. Eng. R 20125

[2] Palmour J ECSCRM 2010 to be published in Mat. Sci. Forum

[3] Hiyoshi T, Kimoto T 2009 Appl. Phys. Exp. 2091101

[4] Dalibor T, Pensl G, Matsunami H, Kimoto T, Choyke W J, Schöner A, Nordell N 1997 Phys.Status Solidi A 162199 
[5] Grillenberger J, Achtziger N, Sielemann R, Witthuhn W 2000 J.Appl.Phys. 883260

[6] Negoro Y, Kimoto T, Matsunami H 2004 Appl.Phys.Lett. 851716

[7] Alfieri G, Monakhov E V, Svensson B G, Linnarsson M 2005 J.Appl.Phys. 9843518

[8] Danno K, Kimoto T, Matsunami H 2005 Appl.Phys.Lett. 86122104

[9] K. Danno K, Kimoto T 2007J.Appl.Phys. 101103704

[10] Alfieri G, Kimoto T 2007 J.Appl.Phys. 101103716

[11] Alfieri G, Kimoto T 2007 J.Phys.:Condens.Matter 19306204

[12] Alfieri G, Kimoto T, 2008Appl.Phys.Lett. 93032108

[13] Luo J M, Zhong Z Q, Gong M, Fung S, Ling C C 2009 J.Appl.Phys. 105063711

[14] Storasta L, Bergman J P, Janzén E, Henry A, Lu J 2004 J.Appl.Phys. 964909

[15] Chen X D, Yang C L, Gong M, Ge W K, Fung S, Beling C D, Wang J N, Lui M K, Ling C C 2004 Phys.Rev.Lett $\mathbf{9 2} 125504$

[16] Weiss S, Kassing R, 1988 Solid-State Electron. 311733

[17] Gali A, Hornos T, Son N T, Janzén E, Choyke W J 2007 Phys.Rev.B 75045211 and references therein

[18] Matsuura H, Minohara N, Ohshima T 2008 J.Appl.Phys. 104043702

[19] Bockstedte M, Mattausch A, Pankratov O 2004 Phys.Rev.B 69235202

[20] Gali A, Déak P, Ordejón P, Son N T, Janzén E, Choyke W J 2003 Phys.Rev.B 68125201

[21] Rauls E, Fraunheim Th, Gali A, Déak P,2003 Phys.Rev.B 68155208

[22] Storasta L, Kamata I, Nakamura T, Tsuchida H 2006 Mat. Sci. Forum 527-529 489

[23] Umeda T, Ishoya J, Ohshima T, Morishita N, Itoh H, Gali A 2007 Phys.Rev.B 75245202

[24] Zywietz A, Furthmüller J, Bechstedt F 1999 Phys.Rev.B 5915166

[25] Aboelfotoh M O, Fröjdh C, Pettersson C S 2003 Phys.Rev.B 67075312 